\title{
Optimal Replenishment Policy for Deteriorating and Non-Deteriorating Items
}

\section{Martina Bobalova, Veronika Novotna}

\author{
BUT FBM \\ Kolejní 2906/4, 61200 Brno, Czech Republic \\ E-mail.novotna@fbm.vutbr.cz,novotna@fbm.vutbr.cz. \\ cross $^{\text {ref }}$ http://dx.doi.org/10.5755/j01.ee.29.3.14204
}

\begin{abstract}
The paper aims to present a model which solves the problem of determining the optimum price and management of inventory consisting of durable and deteriorating items. It is a model considering the possibility of a short-term interest-free loan provided to the retailer by a supplier. The model allows the retailer to analyze various strategies and to determine the optimum price of three kinds of products.

The scientific aim of the paper is to verify the solution of an optimization problem and to specify the length of the interval which results in the maximizing the profit from selling two kinds of deteriorating goods and one non-deteriorating item. First, the paper explains the theory required for understanding how the model works, and this is followed by basic scientific methods (analysis, synthesis), analysis of multivariable functions, and dynamic modeling.

The authors analyze situations in which the retailer repays the credit in due time as well as situations in which the due date is not met. As the model enables simulation of different situations and provides exact results, it is also possible to simulate the effect of changes in the values of various variables.

The authors also verified the fact that theorems (věty) for continuous functions may be used for further conclusions since the variables used form a compact set on which the analysed function of more variables is continuous.

Following further analysis, the new model may be generalized, supplemented and made more accurate; for example some discounts or shortage if items may be considered.
\end{abstract}

Keywords: Differential Calculus of Multivariable Functions; Differential Equations; Taylor Series; Replenishment Policy; Deteriorating Items; Non-Deteriorating Items.

\section{Introduction}

One of the current frequently discussed issues related to the pressure for maximum productivity, higher effectiveness of management processes and other internal processes in companies is optimization of inventories. In spite of their positive function, the issue of inventories is of fundamental importance, and the probem of reducing inventiories in order to cut costs is a recurring issue. Nowadays, it is possible to keep accurate records of inventories, so their levels are well known and easily measurable. Inventory levels can even be easily monitored in entire chains of companies. Therefore, inventory management is the focus of attention of numerous specialists in the application of mathematical methods in management.

For many companies, inventory represents the largest investment. Lambert et al. (2000), for instance, state that while in manufacturing companies inventory may account for more that $20 \%$ of the total assets, in trading companies this figure may be higher than $50 \%$. Over the last 20 to 25 years, companies have been under pressure to increase their inventory levels in order to enhance their competitiveness. In an effort to meet needs of diverse market segments, companies have considerably expanded their product ranges. Moreover, customers expect a wide range of goods to be immediately available nowadays. In many cases, this has led to an increase in inventory levels. Inventory management should therefore become a key area with full attention paid to it as it may help to stabilize a company's cash-flow and decrease investment costs.

Inventory management and optimization are common part of day-to-day business processes in a retail company. Customers are very sensitive to any shortcomings related to availability of the products they demand, and their dissatisfaction may influence preferred suppliers in the future. Corsten and Gruen (2004) found out that in $31 \%$ of cases unavailability of goods makes customers look for substitute products in another shop. Another finding showed that in 72 $\%$ of cases the shortage of goods in stock was also due to the store's ordering system. A number of studies deal with inventory management in the retail environment, taking account of such aspects as goods perishability, for example Lim and Hur (2015) or Coelho and Laporte (2014), information accuracy Mersereu (2013) and demand substitution - Yucela et al. (2009) or Tan and Karabati (2012).

This paper aims to design a mathematical model allowing a retailer, under terms agreed in advance (and per unit of goods), to determine the optimum selling price and the maximum length of the interval to sell the goods without a loss. The model assumes that values of certain parameters are known and demand is time-dependent. The model has been developed for two fast deteriorating items of goods and one non-deteriorating item. It is further assumed that inventories are drawn upon customers' request, i.e. on the basis of time-dependent demand. 
The scientific aim of the paper is to verify the solution of the optimization problem and to determine the length of a time interval which maximizes the profit from selling two kinds of deteriorating goods and one kind of non-deteriorating goods. The authors of the paper use basic scientific methods (analysis and synthesis), analysis of multivariable functions, and dynamic modelling.

Using the new model, the authors simulated some variants of possible solutions on real data. The results are presented graphically.

\section{Literature Review}

Many retailers find it difficult to pay for goods they need for their businesses immediately upon obtaining an invoice. Therefore, it is a common practice that a customer is allowed a certain time to settle with the supplier. Such a situation was analyzed by Goyal (1985) in his paper. He created an EOQ model in which a customer is permitted to pay to the supplier with a delay. This model is described, in more general terms, by other authors, such as Sarkar (2012), whose model even allows a shortage of demanded goods in stock. Lin et al. (2012) present an integrated inventory model allowing for the possibility of defective goods. Li et al. (2009) focus on dynamic pricing and non-standard situations arising from inventory control of perishable goods in the final interval. Teng et al. (2012) also mention the assumption of time-dependent demand for goods. The authors are concerned with the optimum quantity to be ordered and the order cycle time in the EOQ system. Guchhait et al. (2013) introduced a new hybrid metaheuristic algorithm, which was designed based on the analysis of the impact of credit for retailers on the quantity of goods ordered. Molamohamadi (2014) used a less common method of inventory management by means of genetic algorithms. Taleizadeh et al. (2013) studied the way goods are paid for, and in their summary of EOQ models they focused on payment made by cash or credit cards. Yu (2013) concludes that if the supplier and the customer cooperate to develop a common strategy, both parties yield higher profits as a result. Inspired by studies by Ouyang et al. (2006) and Jaggi et al. (2008), He and Huang (2013) created an inventory model with a two-echelon credit policy and came up with an algorithm enabling the maximum total profit. Inventory management in supply chains and logistics were studied by Horvat et al. (2015) and by Grundey and Rimiene (2007).

The issue of deteriorating goods was also studied by Bhunia et al. (2014), Das and Mondal (2013), and Yang and Chang (2013), who were primarily concerned with the optimum amount of goods in stock. They also determine a price corresponding to a replenishment strategy, and propose an algorithm to solve the problem. Maihami and Kamalabadi (2012) focus on the management of ,non-instantaneous perishable items" and allow for partial backlogging. The authors try to resolve an optimization problem for a selling price, replenishment plan, and the quantity of goods. Assuming that the demand and price are time-dependent, they present their algorithm. Conditions of a monopoly in case of selling deteriorating goods with two price regimes are explored by Dasu and Tong (2010). Pan and Li (2015), and Li (2014) describe other inventory management problems in their studies.

\section{Model Construction}

Let us study a situation in which a retailer buys two kinds of perishable items and one kind of non-deteriorating item from a supplier who allows the retailer an interest-free delay in payment. The model will help to optimize the selling price required by the retailer and to specify the length of the permissible delay in payment.

Our model is further based on the following assumptions:

- Demand for inventory is a monotone price function, decreasing over time

- No shortages of goods in stock are allowed

- Time horizon is unlimited.

The following variables and their signs will be used in the model:

$H_{i}$ : holding cost per unit (annual, excluding interest charges on overdue payment), $i=1,2,3$,

$c_{\mathrm{i}}$ : purchasing cost per unit, $\mathrm{c}_{i}>0, i=1,2,3$,

$p_{\mathrm{i}}$ : selling price per unit, $c_{i}<p_{i}, i=1,2,3$,

$\theta_{i}$ : deterioration rate; $0<\theta_{i}<1, i=1,2$,

$I_{d}:$ interest received per currency unit per year,

$I_{c}$ : annual interest charges on overdue payment per currency unit per year,

$m$ : period of permissible delay in payment - trade credit period,

$s:$ secondary order cost,

$I_{\mathrm{i}}(t)$ : inventory level at time $t(0 \leq t \leq T)$ for item $i, i=$ $1,2,3$,

$T$ : reorder point $T>0$,

$D_{i}:$ annual demand, where $D_{i}\left(p_{i}, t\right)=\alpha_{i} p_{i}^{-\beta_{i}} t, i=$ $1,2,3$,

We further assume that $\alpha_{i}>0$ and $\beta_{i}>1$, where $\alpha_{i}$ is a scaling factor and $\beta_{i}$ is a price-elasticity coeficient, the simplified notation $a_{i}=\alpha_{i} p_{i}^{-\beta_{i}} i=1,2,3$, Ho et al., (2008)

$Z\left(T, p_{1}, p_{2}, p_{3}\right)$ : total annual profit.

In order to develop models which aim to model real economic phenomena as accurately as possible, we may successfully apply methods based on findings from mathematical disciplines such numerical and statistical methods, operational research, methods of linear or non-linear and dynamic programming, etc. (for example Simankova (2011), David and Krapek (2013), Fumi (2013), Plaček et al. (2015), Doskočil et al (2016)). In this paper we will primarily use analysis of multivariable functions.

It follows from the above mentioned assumptions regarding the behavior of inventory and changes in their levels that the inventory level $I_{i}(t), i=1,2$ is a strictly decreasing function of time, which corresponds to the demand for goods. The change can be described by ordinary differential equations:

$$
\begin{aligned}
& \frac{\mathrm{d} I_{i}(t)}{\mathrm{d} t}+\theta I_{i}(t)=-D_{i}\left(p_{i}, t\right), 0 \leq t \leq T \\
& \text { and therefore } \\
& \frac{\mathrm{d} I_{i}(t)}{\mathrm{d} t}+\theta I_{i}(t)=-a_{i} t, 0 \leq t \leq T,
\end{aligned}
$$$$
\text { where } \mathrm{i}=1,2 \text {. }
$$

The initial condition can be defined as $I_{i}(T)=0$., which corresponds to a situation in which all items of goods have been drawn at the end of the order cycle. 
Having solved the differential equations specified above, we may conclude that a retailer sells $\frac{a_{i} T}{2}$ units of goods and purchases the total of $\frac{a_{i}\left(-e^{\theta_{i} T}+\theta_{i} T e^{\theta_{i} T}+1\right)}{T \theta_{i}^{2}}$ units of goods per year.

The credit amounts to the value of $\frac{c_{i} a_{i}\left(-e^{\theta_{i} T}+\theta_{i} T e^{\theta_{i} T}+1\right)}{T \theta_{i}^{2}}$ and it must be repaid to the supplier.

Assumptions similar to the previous case can be formulated for non-deteriorating goods. Therefore, a change in inventory in dependence on time can be expressed by the following:

$$
\begin{aligned}
& \frac{d \mathrm{I}_{3}(\mathrm{t})}{d t}=-D_{3}\left(p_{3}, t\right), 0 \leq t \leq T \\
& \frac{d \mathrm{I}_{3}(\mathrm{t})}{d t}=-a_{3} t, 0 \leq t \leq T
\end{aligned}
$$

the initial condition is defined as $I_{3}(T)=0$.

Within one business cycle a retailer sells $\frac{a_{3} T^{2}}{2}$ items of goods in total, and $\frac{a_{3} T}{2}$ per year. The retailer has to repay the whole supplier's credit in full, the payment of $\frac{c_{3} a_{3} T^{2}}{2}$, which is the total of $\frac{c_{3} a_{3} T}{2}$ per year.

For further calculations regarding the cost interest and yield interest, the authors chose the approach from publication Goyal (1985).

Total annual variable costs consist of the following items:

- ordering costs,

- warehousing costs,

- interest costs for stocking items,

- $\quad$ interest gained during the settlement period.

\section{Process to Determine the Extremes}

In order to determine the maximum gain, we have to verify if the yield function has an extreme end and, if it does, whether it is the maximum value. In out model it is a function with more variables.

If function $Z$ has partial derivatives of the first order, then function $Z$ may have a local extreme (local minimum or maximum) at point $X=\left[T^{0}, p_{1}^{0}, p_{2}^{0}, p_{3}^{0}\right]$ only if

$$
\frac{\partial Z}{\partial T}(X)=0, \frac{\partial Z}{\partial p_{1}}(X)=0, \frac{\partial Z}{\partial p_{2}}(X)=0, \frac{\partial Z}{\partial p_{3}}(X)=0 .
$$

Furthermore, let function $Z$ have continuous partial derivatives of the second order in the vicinity of point $X$. Let us denote

$$
\begin{gathered}
Z^{\prime \prime}(X)= \\
\left(\begin{array}{cccc}
\frac{\partial^{2} Z}{\partial T^{2}} & \frac{\partial^{2} Z}{\partial T \partial p_{1}} & \frac{\partial^{2} Z}{\partial T \partial p_{2}} & \frac{\partial^{2} Z}{\partial T \partial p_{3}} \\
\frac{\partial^{2} Z}{\partial p_{1} \partial T} & \frac{\partial^{2} Z}{\partial p_{1}^{2}} & \frac{\partial^{2} Z}{\partial p_{1} \partial p_{2}} & \frac{\partial^{2} Z}{\partial p_{1} \partial p_{3}} \\
\frac{\partial^{2} Z}{\partial p_{2} \partial T} & \frac{\partial^{2} Z}{\partial p_{2} \partial p_{1}} & \frac{\partial^{2} Z}{\partial p_{2}^{2}} & \frac{\partial^{2} Z}{\partial p_{2} \partial p_{3}} \\
\frac{\partial^{2} Z}{\partial p_{3} \partial T} & \frac{\partial^{2} Z}{\partial p_{3} \partial p_{1}} & \frac{\partial^{2} Z}{\partial p_{3} \partial p_{2}} & \frac{\partial^{2} Z}{\partial p_{3}^{2}}
\end{array}\right)(X)
\end{gathered}
$$

the matrix of second partial derivatives of the function $Z$ at the point $X$. Such matrix $Z^{\prime \prime}(X)$ is symmetrical. If all its main minors are positive ( $Z$ is positive definite), then the function $Z$ has a strict local minimum at the point $X$. If its odd-order main minors are negative and the even-order main minor is positive ( $Z$ is negative definite), the function $Z$ has a strict local maximum at the point $X$.

\section{Discussion for Individual Cases}

\section{Analysis of Such a Situation in Which the Items Are Sold in Time}

\section{a) Order of deteriorating goods only}

If $T \leq m$, then the retailer has no additional costs.

By using the first three terms of the Taylor expansion, the total annual profit may be expressed in the form of an equation which considerably simplifies the subsequent numerical computations

$$
\begin{aligned}
& Z D 1=Z D 1\left(T, p_{1}, p_{2}\right)= \\
& =\frac{p_{1} a_{1} T}{2}-\frac{c_{1} a_{1}\left(-\left(1+\theta_{1} T+\frac{\theta_{1}{ }^{2} T^{2}}{2}\right)+\theta_{1} T\left(1+\theta_{1} T+\frac{\theta_{1}{ }^{2} T^{2}}{2}\right)+1\right)}{T \theta^{2}} \\
& -\frac{H a_{1}\left(-T^{2} \theta_{1}{ }^{2}+2\left(1+\theta_{1} T+\frac{\theta_{1}{ }^{2} T^{2}}{2}\right) T \theta_{1}-2\left(1+\theta_{1} T+\frac{\theta_{1}{ }^{2} T^{2}}{2}\right)+2\right)}{2 \theta_{1}{ }^{3}} \\
& +\mathrm{p}_{1} \mathrm{I}_{\mathrm{d}}\left(\frac{-\mathrm{a}_{1} \mathrm{~T}(\mathrm{~T}-\mathrm{m}-1)}{2}\right)+\frac{\mathrm{p}_{2} \mathrm{a}_{2} \mathrm{~T}}{2} \\
& -\frac{c_{2} a_{2}\left(-\left(1+\theta_{2} T+\frac{\theta_{2}{ }^{2} T^{2}}{2}\right)+\theta_{2} T\left(1+\theta_{2} T+\frac{\theta_{2}{ }^{2} T^{2}}{2}\right)+1\right)}{T \theta^{2}} \\
& -\frac{H a_{2}\left(-\mathrm{T}^{2} \theta_{2}{ }^{2}+2\left(1+\theta_{2} T+\frac{\theta_{2}{ }^{2}}{2}\right) T \theta_{2}-2\left(1+\theta_{2} T+\frac{\theta_{2}{ }^{2} T^{2}}{2}\right)+2\right)}{2 \theta_{2}{ }^{3}} \\
& \quad+p_{2} I_{d}\left(\frac{-a_{2} T(T-m-1)}{2}\right)-\frac{s}{T}
\end{aligned}
$$

It follows from equation (7) that for arbitrary positive $T, p_{1}$ and $p_{2}$ the function $Z D 1$ is a continuous function of three variables.

\section{b) Order of non-deteriorating goods only}

In this case no costs interest is paid either.

The total annual profit can be expressed as follows: $Z N D 1\left(T, p_{3}\right)=\frac{p_{3} a_{3} T}{2}-\frac{s}{T}-\frac{c_{3} a_{3} T}{2}-\frac{H a_{3} T^{2}}{2}+a_{3} p_{3} I_{d}\left(m-\frac{T}{2}\right)$. (8)

For arbitrary non-negative $T$ and $p_{3}$ the function $Z N D 1$ is continuous.

\section{c) Order of both kinds of goods}

If both deteriorating and non-deteriorating goods are ordered, the yield function will be the following:

$$
\begin{gathered}
Z 1=Z 1\left(T, p_{1}, p_{2}, p_{3}\right)= \\
=\frac{p_{1} a_{1} T}{2}-\frac{c_{1} a_{1}\left(-\left(1+\theta_{1} T+\frac{\theta_{1} T^{2}}{2}\right)+\theta_{1} T\left(1+\theta_{1} T+\frac{\theta_{1}{ }^{2} T^{2}}{2}\right)+1\right)}{T \theta^{2}} \\
-\frac{H a_{1}\left(-T^{2} \theta_{1}{ }^{2}+2\left(1+\theta_{1} T+\frac{\theta_{1}{ }^{2} T^{2}}{2}\right) T \theta_{1}-2\left(1+\theta_{1} T+\frac{\theta_{1}{ }^{2} T^{2}}{2}\right)+2\right)}{2 \theta_{1}{ }^{3}} \\
+\mathrm{p}_{1} \mathrm{I}_{\mathrm{d}}\left(\frac{-\mathrm{a}_{1} \mathrm{~T}(\mathrm{~T}-\mathrm{m}-1)}{2}\right)+\frac{\mathrm{p}_{2} \mathrm{a}_{2} \mathrm{~T}}{2} \\
-\frac{c_{2} a_{2}\left(-\left(1+\theta_{2} T+\frac{\theta_{2}{ }^{2} T^{2}}{2}\right)+\theta_{2} T\left(1+\theta_{2} T+\frac{\theta_{2}{ }^{2} T^{2}}{2}\right)+1\right)}{T \theta^{2}} \\
-\frac{H a_{2}\left(-\mathrm{T}^{2} \theta_{2}{ }^{2}+2\left(1+\theta_{2} T+\frac{\theta_{2}{ }^{2} T^{2}}{2}\right) T \theta_{2}-2\left(1+\theta_{2} T+\frac{\theta_{2}{ }^{2} T^{2}}{2}\right)+2\right)}{2 \theta_{2}{ }^{3}} \\
+p_{2} I_{d}\left(\frac{-a_{2} T(T-m-1)}{2}\right)-\frac{s}{T}+\frac{p_{3} a_{3} T}{2}-\frac{c_{3} a_{3} T}{2}-\frac{H a_{3} T^{2}}{2} \\
+a_{3} p_{3} I_{d}\left(m-\frac{T}{2}\right)
\end{gathered}
$$

\section{Maximizing Functions $Z N D 1, Z D 1, Z 1$}

For our model, values of variables $T$ and $p_{i}$ may be limited to the set

$$
O=\left\{\left[T, p_{i}\right] \mid T \in[1, T \max ], p_{i} \in\left[c_{i}, p_{i} \max \right]\right\} .
$$

Constraints arising from the economic nature of the problem represent a compact set in the space of variables $T$ and $p_{i}$. Functions $Z D 1$ and $Z N D 1$ are continuous on this set. 
Given these assumption, we may infer, using the Weierstrass Theorem (a precise definition can be found e.g. in Došla and Kuben, (2012)), that functions $Z D 1$ and $Z N D 1$ have extremes on the above-specified set $O$. These variables reach minimum or maximum values either at points of local extremes or on the boundary of the compact set.

Since $\frac{\partial^{2} \mathrm{ZD} 1\left(\mathrm{~T}, \mathrm{p}_{1}, \mathrm{p}_{2}\right)}{\partial \mathrm{T}^{2}}<0$ and $\frac{\partial^{2} \mathrm{ZND} 1\left(\mathrm{~T}, \mathrm{p}_{3}\right)}{\partial \mathrm{T}^{2}}<0$, the function $Z D 1$ and $Z N D 1$ are concave functions in the given set, and therefore any of its extremes must be its maximum.

As functions $Z D 1$ and $Z N D 1$ are continuous on set $O$, even their linear combination is continuous. And since functions $Z D 1$ and $Z N D 1$ have, according to the Weistrass theorem, extreme values on set $O$, so does function $Z 1$. Moreover, as functions $Z D 1$ and $Z N D 1$ are concave on $O$ and they even have a continuous second-order differential, the same applies to function $Z 1$, and, as follows from the relevant criteria, function $Z 1$ is concave on $O$.

If we assume that values of $p_{1}, p_{2} a p_{3}$ are known, we are able to calculate the value of $T$, which, if exceeded, causes the retailer to sustain a loss. The value is obtained by making the yield function equal zero regardless of which of the abovementioned cases is in question. Due to the scope and complicated analytical formulation the calculation is not provided in the paper.

\section{Analysis of a Situation in Which the Items Are Sold too Late}

\section{a) Order of deteriorating goods only}

If $T \geq m$, the retailer must take a credit at time $m$, on which credit annual interest must be paid amounting to

$$
\begin{aligned}
& \frac{I_{c} p_{1} a_{1}\left(m^{2} \theta_{1}{ }^{2}+2 T \theta_{1} e^{\theta_{1}(T-m)}-2 m \theta_{1}-T^{2} \theta_{1}{ }^{2}-2 e^{\theta_{1}(T-m)}+2\right)}{2 T \theta_{1}{ }^{3}} \\
& +\frac{I_{c} p_{2} a_{2}\left(m^{2} \theta_{2}{ }^{2}+2 T \theta_{2} e^{\theta_{2}(T-m)}-2 m \theta_{2}-T^{2} \theta_{2}{ }^{2}-2 e^{\theta_{2}(T-m)}+2\right)}{2 T \theta_{2}{ }^{3}}
\end{aligned}
$$

Nevertheless, the retailer may gain annual interest on the deposit of the sales received before time $m$, which equals $\frac{a_{1} m^{2} I_{d}+a_{2} m^{2} I_{d}}{2 T}$.

Given the demanding calculation, we shall use the following simplification - using the first three terms of the Taylor expansion, the total annual profit may be expressed as follows:

$$
\begin{gathered}
Z D 2=Z D 2\left(T, p_{1}, p_{2}\right)= \\
\frac{p_{1} a_{1} T}{2}-\frac{c_{1} a_{1}\left(\left(1+\theta_{1} T+\frac{\theta_{1}{ }^{2} T^{2}}{2}\right)\left(\theta_{1} T-1\right)+1\right)}{T \theta^{2}} \\
-\frac{H a_{1}\left(-\mathrm{T}^{2} \theta_{1}{ }^{2}+2\left(1+\theta_{1} T+\frac{\theta_{1}{ }^{2} T^{2}}{2}\right) \mathrm{T} \theta_{1}-2\left(1+\theta_{1} T+\frac{\theta_{1}{ }^{2} T^{2}}{2}\right)+2\right)}{2 \theta_{1}{ }^{3}} \\
-\frac{H_{1}\left(-\mathrm{T}^{2} \theta_{2}{ }^{2}+2\left(1+\theta_{2} T+\frac{\theta_{2}{ }^{2} T^{2}}{2}\right) \mathrm{T} \theta_{2}-2\left(1+\theta_{2} T+\frac{\theta_{2}{ }^{2} T^{2}}{2}\right)+2\right)}{2 \theta_{2}{ }^{3}} \\
-I_{c} p_{1} a_{1} \frac{\left(m^{2} \theta_{1}{ }^{2}+2 T \theta_{1}\left(1+\theta_{1}(-m+T)+\frac{\theta_{1}(-m+T)^{2}}{2}\right)-2 m \theta_{1}\right)}{2 T \theta_{1}{ }^{3}} \\
-I_{c} p_{1} a_{1} \frac{\left(T^{2} \theta_{1}{ }^{2}-2\left(1+\theta_{1}(-m+T)+\frac{\theta_{1}(-m+T)^{2}}{2}\right)+2\right)}{2 T \theta_{1}{ }^{3}} \\
-I_{c} p_{2} a_{2} \frac{\left(m^{2} \theta_{2}{ }^{2}+2 T \theta_{2}\left(1+\theta_{2}(-m+T)+\frac{\theta_{2_{1}}(-m+T)^{2}}{2}\right)-2 m \theta_{2}\right)}{2 T \theta_{2}{ }^{3}}
\end{gathered}
$$

$$
\begin{gathered}
-I_{c} p_{2} a_{2} \frac{\left(T^{2} \theta_{2}{ }^{2}-2\left(1+\theta_{2}(-m+T)+\frac{\theta_{21}(-m+T)^{2}}{2}\right)+2\right)}{2 T \theta_{2}{ }^{3}}-\frac{s}{T} \\
+\frac{a_{1} m^{2} I_{d}+a_{2} m^{2} I_{d}}{2 T} .
\end{gathered}
$$

It follows from equation (11) that for arbitrary positive $T, p_{1}$ and $p_{2}$ the function $Z D 2$ is a continuous function of three.

\section{b) Order of non-deteriorating goods only}

In this case the total annual profit can be expressed as follows:

$$
\begin{aligned}
Z N D 2\left(T, p_{3}\right)= & \frac{p_{3} a_{3} T}{2}-\frac{s}{T}-\frac{c_{3} a_{3} T}{2}-\frac{H a_{3} T^{2}}{2} \\
& -\frac{a_{3} p_{3}(T-m)^{2} I c}{2 T}+\frac{a_{3} m^{2} I_{d}}{2 T} .
\end{aligned}
$$

This function allows for the fact that a retailer has to take out a loan at time $m$, on which annual interest of $\frac{a p_{3}(T-m)^{2} I c}{2 T}$ must be paid.

Function $Z N D 2$ is a continuous function for arbitrary $T>$ 0 and $p_{3}>0$.

\section{c) Order of both kinds of goods}

If both deteriorating and non-deteriorating goods are ordered, the yield function will be the following:

$$
\begin{gathered}
Z 2=Z 2\left(T, p_{1}, p_{2}, p_{3}\right)= \\
=\frac{p_{1} a_{1} T}{2}-\frac{c_{1} a_{1}\left(\left(1+\theta_{1} T+\frac{\theta_{1}{ }^{2} T^{2}}{2}\right)\left(\theta_{1} T-1\right)+1\right)}{T \theta^{2}} \\
-\frac{H a_{1}\left(-T^{2} \theta_{1}{ }^{2}+2\left(1+\theta_{1} T+\frac{\theta_{1}{ }^{2} T^{2}}{2}\right) \mathrm{T} \theta_{1}-2\left(1+\theta_{1} T+\frac{\theta_{1}{ }^{2} T^{2}}{2}\right)+2\right)}{2 \theta_{1}{ }^{3}} \\
+\frac{p_{2} a_{2} T}{2}-\frac{c_{2} a_{2}\left(\left(1+\theta_{2} T+\frac{\theta_{2}{ }^{2} T^{2}}{2}\right)\left(\theta_{2} T-1\right)+1+1\right)}{T \theta_{2}{ }^{2}} \\
-\frac{H a_{1}\left(-\mathrm{T}^{2} \theta_{2}{ }^{2}+2\left(1+\theta_{2} T+\frac{\theta_{2}{ }^{2} T^{2}}{2}\right) \mathrm{T} \theta_{2}-2\left(1+\theta_{2} T+\frac{\theta_{2}{ }^{2} T^{2}}{2}\right)+2\right)}{2 \theta_{2}{ }^{3}} \\
-I_{c} p_{1} a_{1} \frac{\left(m^{2} \theta_{1}{ }^{2}+2 T \theta_{1}\left(1+\theta_{1}(-m+T)+\frac{\theta_{1}(-m+T)^{2}}{2}\right)-2 m \theta_{1}\right)}{2 T \theta_{1}{ }^{3}} \\
-I_{c} p_{1} a_{1} \frac{\left(T^{2} \theta_{1}{ }^{2}-2\left(1+\theta_{1}(-m+T)+\frac{\theta_{1}(-m+T)^{2}}{2}\right)+2\right)}{2 T \theta_{1}{ }^{3}} \\
-I_{c} p_{2} a_{2} \frac{\left(m^{2} \theta_{2}{ }^{2}+2 T \theta_{2}\left(1+\theta_{2}(-m+T)+\frac{\theta_{2_{1}}(-m+T)^{2}}{2}\right)-2 m \theta_{2}\right)}{2 T \theta_{2}{ }^{3}} \\
-I_{c} p_{2} a_{2} \frac{\left(T^{2} \theta_{2}{ }^{2}-2\left(1+\theta_{2}(-m+T)+\frac{\theta_{2_{1}}(-m+T)^{2}}{2}\right)+2\right)}{2 T \theta_{2}{ }^{3}} \\
+\frac{a_{1} m^{2} I_{d}+a_{2} m^{2} I_{d}}{2 T}+\frac{p_{3} a_{3} T}{2}-\frac{s}{T}-\frac{c_{3} a_{3} T}{2}-\frac{H a_{3} T^{2}}{2} \\
-\frac{a_{3} p_{3}(T-m)^{2} I c}{2 T}+\frac{a_{3} m^{2} I_{d}}{2 T} .
\end{gathered}
$$

\section{Maximizing Functions ZND2, ZD2, Z2}

The same assumptions which hold for functions $Z D 1$ and $Z N D 1$, also hold for functions $Z D 2$ and $Z N D 2$ in the set

$O=\left\{\left[T, p_{i}\right] \mid T \in[1, T \max ], p_{i} \in\left[c, p_{i} \max \right]\right\}$,

Since $\frac{\partial^{2} \mathrm{Z} 2\left(\mathrm{~T}, \mathrm{p}_{1}, \mathrm{p}_{2}\right)}{\partial \mathrm{T}^{2}}<0$ and $\frac{\partial^{2} \mathrm{ZND} 2\left(\mathrm{~T}, \mathrm{p}_{3}\right)}{\partial \mathrm{T}^{2}}<0$, functions $Z D 2$ and $Z N D 2$ are concave functions on the given space, and therefore, if there is an extreme, it must be a maximum. 
As functions $Z D 2$ and $Z N D 2$ are continuous on set $O$, even their linear combination is continuous. And if the functions have total extreme values, so does function $Z 2$. Moreover, as functions $Z D 2$ and $Z N D 2$ are concave on $O$ and they even have a continuous second-order differential, the same applies to function $Z 2$, and function $Z 2$ is concave $O$.

Assuming that values of $p_{1}, p_{2} a p_{3}$ are known, we are able to calculate the value of $T$, which, if exceeded, causes the retailer to sustain a loss. The value is obtained by making the yield function equal zero regardless of which of the abovementioned cases is in question. Due to the scope and complicated analytical formulation the calculation is not provided in the paper.

\section{Illustrative Example}

The illustrative example stems from a real situation and deploys data of a company which supplies its goods in food vending machines. Let us have two kinds of deteriorating goods and one kind of durable goods.

Based on the data provided by the company, parameters' values were specified in the following way:

$I_{c}=0.10$ (currency units per year, hereinafter currency units will be referred to as CUS), $I_{d}=0.01$ (CUS per year), $c_{1}=19.0$ (CUS per year), $s=120.0$ (CUS per piece), $m=$ $10 / 365$

For deteriorating goods:

$H_{D}=1$ (units per year), $c_{1}=19.0$ (CUS per year), $s=$ 120.0 (CUS per year), $\alpha_{1}=7300000, \beta_{1}=1.70, \alpha_{2}=$ $7200000, \beta_{2}=1.80, c_{2}=22$ (CUS per year), $\theta_{1}=$ $0.10, \theta_{2}=0.07$. Both items of deteriorating goods are supplied at the same time and by the same supplier.

Another condition has to be added that the price of goods " 2 " is capped and can only exceed the price of goods " 1 " by $20 \%$. Should this rule be breached, customers will cease to demand goods " 2 ". It is further necessary to allow for the goods' limited durability, hence the maximum selling time $T<30 / 365$.

For non-deteriorating goods:

$H_{N D}=1.0$ (CUS per year), $c_{3}=19.0$ (CUS per year), $s_{3}=120.0$ (CUS per piece), $\alpha_{3}=7300000, \beta_{3}=1.70$.

For non-deteriorating goods, the price is, based on experience, capped by value 1 monetary unit. If the value is exceeded, the goods will not be sellable.

Given the conditions of the model situation, we may further assume that the goods are sold at a higher price than their purchasing price was. At the same time, we shall assume that the goods can be sold on the first day at the earliest, i.e. $T>$ 0 .

All the computations were carried out with the Maple System. Maple is a popular mathematical program enabling symbolic computations. Unlike Mathematica and Maxima, Maple offers many more functions. Not only is Maple able to perform analytical calculations with formulas, but it can also manage numerical computations and offers graphical representation of results. Its attractive environment is very convenient for users. Maple provides a wide range of possibilities for the use of quantitative methods in practice, scientific calculations, and applications in other areas.

\section{Items are Sold and Credit is Paid Back in Time}

a) Order of non-deteriorating goods only

If a retailer expects to sell the goods in time, they maximize their profit if the replenishment period is $T=0.027$, i.e. 10 days, and the price is $p_{3}=1.09$. As the price has been capped by the company, let us assume price $p_{3}=1$. After verification, the findings that value $T$ has not changed, thus $T=0.027$.

Having substituted acquired values $T$ and $p_{3}$ in function $Z N D 1(T)$, we realize that the company will have a profit of 59045.87 monetary units. $Z N D 1(T)=0$ for $T=63$. If the goods were not sold prior to this moment, the retailer would incur a loss. Given the nature of the goods, such a situation may be deemed unrealistic.

Figure No.1 marks out an area demonstrating potential situations which might occur if the retailer pays for the nondeteriorating goods in time. The marked area represents situation for $p_{3}=1$. The graph shows the yield function over time interval $(0 ; 0.027)$ for price $p_{3}<3$. The yield function for $p_{3}=1$ is highlighted.

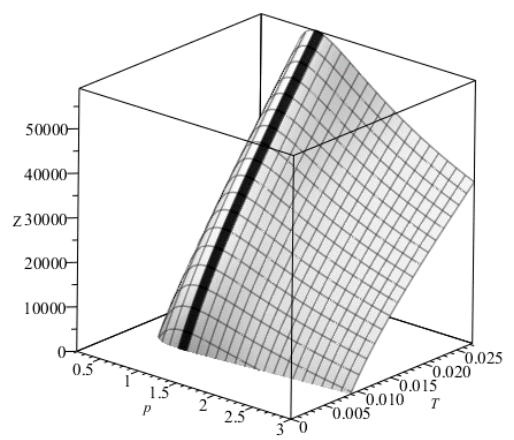

Figure 1. Yield Function for Case a) - Non-Deteriorating Goods are Paid For in Time. Source: Own Calculation

\section{b) Order of deteriorating goods only}

The graph in Figure No. 2 shows situations in which we assume the retailer sells goods successfully, does not suffer a loss, and pays off the credit in due time. Having met specified conditions, the retailer maximizes their profit at $T=0.027$ and $p_{1}=43.9, p_{2}=52.68$. The company's profit is, in this case, 2142.05 monetary units. If the yield function equals zero, we find out that if the goods were not sold prior to time $T=3.89$, the retailer would suffer a loss.

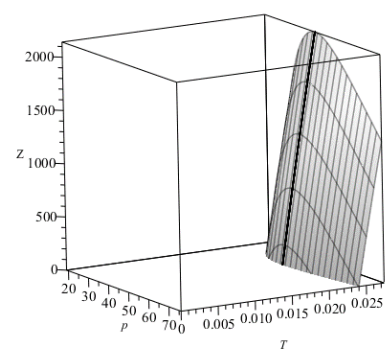

Figure 2. Yield Function for Case b) - Deteriorating Goods are Paid for in Time. Source: Own Calculation

\section{c) Order of both kinds of goods}

Let us assume again that the goods have been sold in time and the loan has also been paid off in time. If both kinds of goods have been ordered at the same time, the retailer 
achieves the maximum profit at time $T=0.027$. The selling price of the non-deteriorating goods remains $p_{3}=1$, but the selling price of the deteriorating goods is $p_{1}=44.15, p_{2}=$ 52.98. The company's profit will be 23657.54 monetary units. The situation can be seen in the yield graph function (Figure No. 3). If the yield function is made to equal zero, we find out that if the goods were not sold prior to time $T=4.15$, the retailer would suffer a loss.

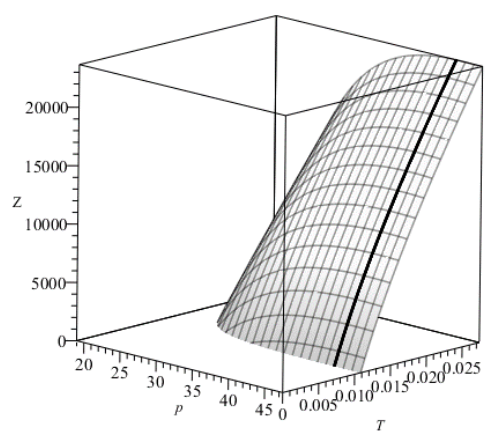

Figure 3. Yield Function for Case c) - Both Kind of Goods are Paid for in Time. Source: Own Calculation

\section{Items are Not Sold and Credit not Paid Back in Time}

\section{d) Order of non-deteriorating goods only}

Figure No.4 shows the yield function graph for a situation in which a retailer does not expect to sell the goods in time, they only maximize the profit if the price of goods is $p_{3}=1$ and the credit is paid off at $T=1.972$, i.e. 719.78 days. In such a case, the profit would be 11018462.66 monetary units. Given the requirement that the goods must be sold on the 30th day at the latest, i.e. $T=0.082$, the profit will only be 69791.12 monetary units. If the demand for executing the sale within 30 days is ignored and if the yield function equals zero, we find out that if time $T=27.82$ were exceeded, the retailer would suffer a loss. However, given the nature of the goods, such a situation may be deemed unrealistic.

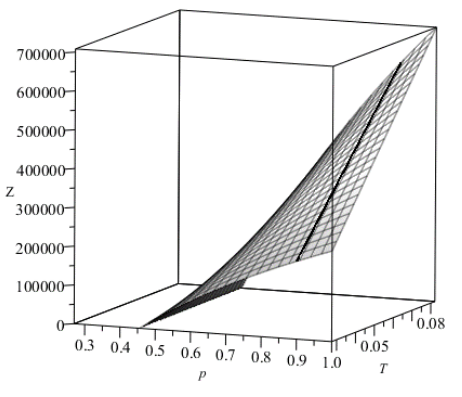

Figure 4. Yield Function for Case d) - Non-Deteriorating Goods are Not Paid for in Time. Source: Own Calculation

\section{e) Order of deteriorating goods only}

Let us now consider a situation in which the retailer is prepared not to meet the terms of the credit and to exceed the credit payback period. In that event, we need to determine the maximum of the function $Z 2$, considering that in case of payment at time $T>m$, the retailer must pay interest charges on overdue payment. If the price reaches $p_{1}=45.0, p_{2}=54.0$ and $T=0.082$, the retailer makes the maximum profit. In this case, the profit will amount to 17492.43 monetary units (see Figure 5). If the yield function is made to equal zero, we find out that if the goods were not sold prior to time $T=3.14$, the retailer would suffer a loss. However, given the initial conditions (deteriorating goods), such a situation cannot occur.

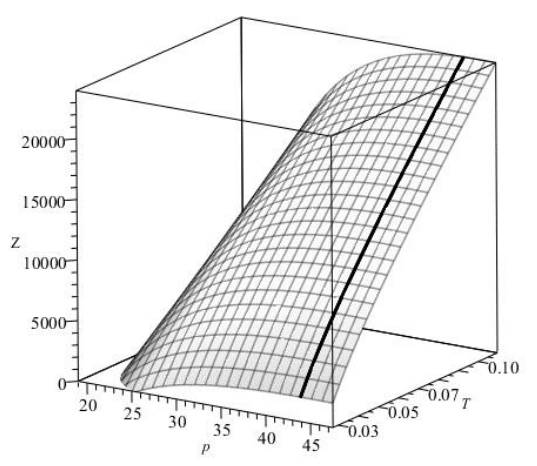

Figure 5. Yield Function for case e) - Deteriorating Goods Are Not Paid for in Time. Source: Own Calculation

\section{f) Order of both kinds of goods}

Let us still assume that the goods have been sold after the credit payment is due and, therefore, the loan will not be paid off. If both kinds of goods have been ordered at the same time, the retailer maximizes their profit at $T=0.082$. The selling price of the non-deteriorating goods remains $p_{3}=1$, but the selling price of the deteriorating goods is $p_{1}=45.0, p_{2}=$ 54.0. The company's profit will be 88148.01 monetary units. The graphic solution of the model situation can be seen in Figure No. 6. If we assume that the goods were not sold prior to time $T=4.97$, the retailer would suffer a loss. This value corresponds to the value obtained by making the yield function equal zero. Such a situation, however, is only hypothetical.

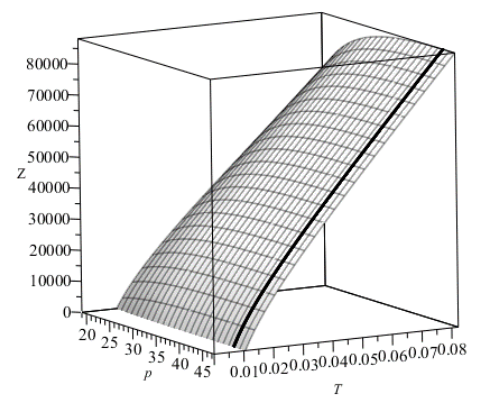

Figure 6. Yield function for case f) - Both kind of goods are not paid for in time. Source: own calculation

\section{Items are expected to be sold in time to meet the credit terms}




\section{g) Order of non-deteriorating goods only}

Let us assume that the retailer has not succeeded in selling the goods in time. This situation is similar to that described in the previous paragraph, i.e. $p_{3}=1, T=0.082$. Therefore, it is not presented in graphics in the paper. Given the requirement that the goods must be sold on the 30th day at the latest, the profit will be 69791.12 monetary units.

\section{h) Order of deteriorating goods only}

In this situation we assume that the retailer expects to sell the goods in time. Due to current state of affairs the retailer does not meet the terms of contract and exceeds the term of payment. The graph shows a case in which the original terms were determined in the same way as in the first case $\left(p_{1}=\right.$ $43.9, p_{2}=52.68$ ). Figure No. 7 shows a situation in which the retailer was expected to repay the credit at time $T=$ 0.274 . However, the due date was not met and the retailer is obliged to pay interest charges on overdue payment. The company's profit is 17492.43 monetary units. If the yield function is made to equal zero, we find out that the retailer would only suffer a loss if the goods were on offer till time $T=43.9$, which exceeds the time limit stemming from defectiveness of the goods.

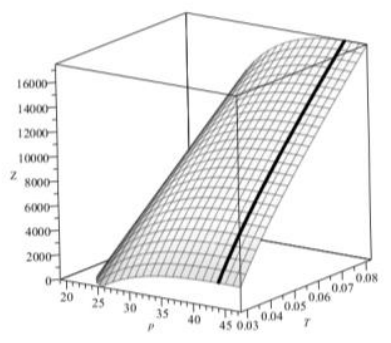

Figure 7. Yield function for case h) - The retailer has not sold the deteriorating goods in time. Source: own calculation

\section{i) Order of both kinds of goods}

If the retailer orders both kinds of goods, the selling price of the non-deteriorating goods remains $p_{3}=1$. The selling price of the deteriorating goods will be $p_{1}=44.15, p_{2}=$ 52.98 and, as can be seen in Figure No. 8, the total company's profit will be 88148.02 monetary units. The retailer would only suffer a loss if the goods were on offer till time $T=$ 4.87, which again exceeds the sell-by time.

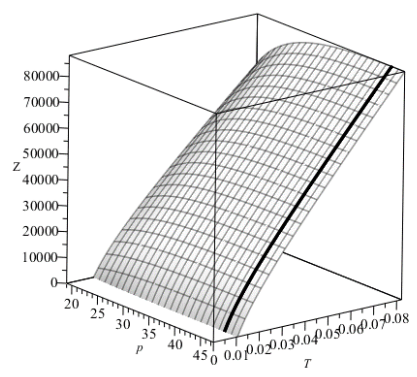

Figure 8. Yield Function for Case i) - The Retailer has Not Succeeded in Selling Both Kind of Goods in Time. Source: Own Calculation

If we analyze the graphic representation of all the above-mentioned cases a-i, we may conclude that from the point of view of profit maximization, it is always beneficial (useful) for a retailer, under given circumstances, to set the maximum value of parameter " $\mathrm{T}$ ". Therefore, a retailer would benefit from negotiating the maximum credit period.

\section{Conclusion}

Modelling real economic problems is very demanding and we are often faced with the fact that both quantities and relations among them change in time. If we are to comprise the dynamism of processes in the model, it is convenient to regard time as a continuous quantity, which is true. Mathematical analysis may be applied to seek solutions to such models.

This paper introduced a model that deals with calculation of an optimum price and the maximum credit repayment period in situation in which both deteriorating and non-deteriorating goods are delivered to the warehouse, and if the supplier allows delayed payments. Using differential calculus of functions of more variables, we analyzed situations in which the retailer sells all the goods in time, and those in which the credit payback period was not meet. We considered cases in which either only deteriorating goods or only non-deteriorating goods were ordered, or in which both deteriorating and non-deteriorating goods were ordered. It was verified that under given conditions the yield function has an extreme value. It was further verified that under such conditions the yield function is concave in both cases; therefore, it is its maximum. Consequently, it is possible to determine the optimum price and the optimum length of the interval in order to maximize the profit. The calculations were made by means of the theory of multivariable functions and approximation by Taylor polynomials (the first three terms of the series were used).

Theoretical findings were shown in the application part, which also demonstrated construction of the model and ways of solving a specific case.

The data were provided by a real company and the goods considered were two kinds of deteriorating goods and one kind of non-deteriorating goods. When modelling various situations, the authors respected limitations imposed on price, following from the company's experience. The situations which were modelled are described in the theoretical part, and the solutions are presented graphically using simulations in Maple.

The model proposed in the paper can be extended in the future. One way is to consider generalization of the model allowing for shortage of goods, quantity discounts, inflation, etc. 


\section{Acknowledgement}

This paper was supported by grant Czech Science Foundation. Name of the Project:” Development of new methods of solving dynamic models of corporate processes management” GA16-03796S.

\section{References}

Bhunia, A. K., \& all. (2014). A two-warehouse inventory model for deteriorating items under permissible delay un payments with partial blacklogging. Appled Mathematics and Computation, 232, $1125-1137$. https://doi.org/10.1016/j.amc.2014.01.115

Coelho, L. C., \& Laporte, G. (2014). Optimal joint replenishment, delivery and inventory management policies for perishable products. Computers \& Operations Research, 47, 42-52. https://doi.org/10.1016/j.cor.2014.01.013

Corsten, D., \& Gruen, T. (2004). Stock-outs cause walkouts. Harvard Business Review, 82(5), $26-28$.

Das, B. C., Das, B., \& Mondal, S. K. (2013). Integrated supply chain model for a deteriorating item with procurement cost dependent credit period. Computers and Industrial Engineering, 64(3), 788-796. https://doi.org/10.10 16/j.cie.2012.12.020

Dasu, S., \& Tong, C. (2010). Dynamic pricingwhen consumers are strategic: Analysis of posted and contingent pricing schemes. European Journal of Operational Research, 204(3), 662-671. https://doi.org/10.1016/j.ejor.2009.11.018

David, P., \& Krapek, M. (2013). Older motor vehicles and other aspects within the proposal of environmental tax in the Czech republic, Acta Univ. Agric. Silvic. Mendel. Brun. 61, 7, 2033-2043. https://doi.org/10.11118/ac$\operatorname{taun} 201361072033$

Fumi, A., \& all. (2013). Fourier analysis for demand forecasting in fashion company. International Journal of Engineering Business Management. 5, 1-10. https://doi.org/10.5772/56839

Goyal, S.K. (1985). Economic order quantity under conditions of permissible delay in payments. Journal of the Operational Research Society, 36, 335-338. https://doi.org/10.1057/jors.1985.56

Grundey, D., \& Rimiene, K. (2007). Logistics centre concept through evolution and definition. Inzinerine EkonomikaEngineering Economics(4), 87-95.

Guchhait, P., \& all. (2013). "Two storage inventory model of a deteriorating item with variable demand under partial credit period. Applied Soft Computing, 13(1), 428-448. https://doi.org/10.1016/j.asoc.2012.07.028

He, Y., \& Huang, H. (2013). Two-level credit financing for noninstantaneous deterioration items in a supply chain with downstream credit-linked demand. Discrete Dynamics in Nature and Society, 2013, $1-22$. https://doi.org/10.1155/2013/917958

Ho, C., Ouyang L., \& Su C. (2008). Optimal pricing, shipment and payment policy for an integrated supplier-buyer inventory model with two-part credit. European Journal of Operational Research, 187, 497-510. https://doi.org/10.1016/j.ejor.2007.04.015

Horvat, A., \& all. (2015). A New Perspective on Quality Characteristics Determining Supply Chain Management of Coffee Produc-tion. Inzinerine Ekonomika-Engineering Economics, 26(3), 239-244. https://doi.org/10.57 55/j01.e e.26.3.5462

Jaggi, C. K., \& all. (2008). Retailer's optimal replenishment decisions with credit-linked demand under permissible delay in payments. European Jour.l of Operational Res., 190(1), 130-135. https://doi.org/10.1016/j.ejor.2007.05.042

Lambert, D., \& all. (2000). Logistics. Praha, Computer Press, 589 p., ISBN 80-722-6221-1.

Li, S. (2014). Optimal control of the production-inventory system with deteriorating items and tradable emission permits. International Journal of Systems Science, 45 (11), 2390-2401. https://doi.org/10.1080/00207721.2013.770103

Li, Y., \& all. (2009). Pricing and inventory control for a perishable product. Manufacturing and Service Operations Management, 11(3), 538-542. https://doi.org/10.1287/msom.1080.0238

Lim, S. Y. \& Hur, S. (2015). Determination of Optimal Shipping Quantity for Perishable Goods under Probabilistic Supply. Mathe-matical Problems in Engineering, vol. 2015. https://doi.org/10.1155/2015/274713 
Lin, Y. J., \& all. (2012). A joint optimal ordering and delivery policy for an integrated supplier-retailer inventory model with trade credit and defective items. Applied Mathematics and Computation, 218(14), 7498-7514. https://doi.org/10.1016/j.amc.2012.01.016

Maihami, R., \& Kamalabadi, I. N. (2012). Joint pricing and inventory control for non-instantaneous deteriorating items with partial backlogging and time and price dependent demand. International Journal of Production Economics, 136(1), 116-122. https://doi.org/10.1016/j.ijpe.2011.09.020

Mersereau, A. J. (2013). Information-Sensitive Replenishment when Inventory Records are Inaccurate. Production and Operations Management, 22(4), 792-810. https://doi.org/10.1111/j.1937-5956.2011.01305.x

Molamohamadi, Z., \& all. (2014). An EPQ inventory model with allowable shortages for deteriorating items under trade credit policy. Discrete Dynamics in Nature and Society, 2014. https://doi.org/10.1155/2014/476085

Ouyang, L. Y., \& all. (2006). A study on an inventory model for non-instantaneous deteriorating items with permissible delay in payments. Computers \& Industrial Eng., 51(4), 637-651. https://doi.org/10.1016/j.cie.2006.07.012

Pan, X., \& Li, S. (2015). Optimal control of a stochastic production-inventory system under deteriorating items and environmental constrains. International Journal of Production Research, 53(2), 607-628. https://doi.org/10.1080/00207543.2014.961201

Placek, M., \& all. (2015). Benchmarking in Czech higher education: the case of schools of economics. Journal Of Higher Education Policy And Management, 37(4), 374-384. https://doi.org/10.1080/1360080X.2015.1056601

Sarkar, B., (2012). And EOQ model with delay in payments and stock demendent demand in the presence of imperfect production. Applied Mathematics and Compitation, 218(17), 8295-8308. https://doi.org/10.1016/j.amc.2012.01.053

Simankova, M. (2011). The Prediction Model - Tool of Choice and Creation of the Payment System. Trends Ekonomics and management. 5(8), $148-155$.

Taleizadeh, A. A., \& all. (2013). An EOQ model with partial delayed payment and partial backordering. Omega, 41(2), 354-368. https://doi.org/10.1016/j.omega.2012.03.008

Tan, B., \& Karabati, S. (2012). Retail inventory management with stock-out based dynamic demand substitution. International Journal of Production Economics, 145(1), 78-87. https://doi.org/10.1016/j.ijpe.2012.10.002

Teng, J. T., Min, J., \& Pan, Q. (2012). Economic order quantity model with trade credit financing for non-decreasing demand. Omega, 40(3), 328-335. https://doi.org/10.1016/j.omega.2011.08.001

Yang, H. L., \& Chang, C. T. (2013). A two-warehouse partial backlogging inventory model for deteriorating items with permissible delay in payment under inflation. Applied Mathematical Modelling, 37(5), 2717-2726. https://doi.org/10.1016/j.apm.2012.05.008

Yu, J. C. P. (2013). A collaborative strategy for deteriorating inventory system with imperfect items and supplier credits. Interna-tional Journal of Production Economics, 143(2), 403-409. https://doi.org/10.1016/j.ijpe.2011.11.018

Yucela, E., \& all. (2009). Optimizing product assortment under customer-driven demand substitution. European Journal of Operational Research, 199(3), 759-768. https://doi.org/10.1016/j.ejor.2008.08.004

The article has been reviewed. Received in February, 2016; accepted in May, 2018. 